\title{
NutriNet-Salud Mexico. Prospective study online: 2018-2028. Relationship between nutrition and health and determinants of dietary habits and nutritional status
}

\author{
NutriNet-Salud México. Estudio prospectivo en línea: 2018-2028. Relación entre nutrición \\ y salud y determinantes de hábitos alimentarios y estado nutricional
}

Jorge Armando Barriguete-Meléndez ${ }^{1,2,3 *}$, Serge Hercberg ${ }^{2}$, Pilar Galán ${ }^{4}$, André Parodi ${ }^{5}$,
Jacques Baulieux ${ }^{5}$ and RED Nutrinet-Salud México ${ }^{6}$
${ }^{1}$ Instituto Nacional de Ciencias Médicas y Nutrición; ${ }^{2}$ Consejo Estratégico Franco Mexicano; ${ }^{3}$ Academia Mexicana de Cirugía. Ciudad de México,
Mexico; ${ }^{4}$ Université Sorbonne Paris Cité; ${ }^{5}$ Académie Nationale de Médecine. Paris, France; ${ }^{6}$ RED Nutrinet-Salud México (see acknowledgements)

\begin{abstract}
Background: NutriNet-Salud Mexico is a digital health information system, e-epidemiology instrument, online, open and free, to recording and analysis the determinants of dietary habits and nutritional status of the Mexican population, for the prevention of overweight, obesity and noncommunicable diseases for the period 2018-2028. Objective: Describe the design, development and implementation of NutriNet-Salud Mexico from the French model NutriNet-Santé France 2008-2018. Method: NutriNet-Salud Mexico platform is the basis for the development of health information system for prospective cohort study, scheduled for a period of 10 years (2018-2028), with a dedicated website, and its development will enable to have multiple study populations within an initial set of five self-applicable questionnaires validated in Mexican population. Results: The information will enable to develop applied research, learn and monitor food contributions and nutritional status of the population, assess the impact of public health actions on feeding behavior and nutritional status, comparing populations between countries (Mexico, France, Belgium and Switzerland) and national institutes, universities and states. Conclusions: NutriNet-Salud Mexico will provide information for assist in research and public action, especially to guide public policies on nutrition Mexico. The scientific elements will make appropriate nutritional recommendations to different populations and access to a representative nominal population sample with low-cost, in real-time, and with dual approach to e-epidemiology: cohort study to identify causality and cross-sectional studies (descriptive research, monitoring and evaluation).
\end{abstract}

KEY WORDS: NutriNet-Salud México. Health information system. Nutrition. Obesity. Noncommunicable diseases.

\section{Resumen}

Introducción: NutriNet-Salud México es un sistema de información en salud digital, instrumento de e-epidemiología, en línea, abierto y gratuito, para el registro y el análisis de los factores determinantes de los hábitos alimentarios y el estado nutricional de la población mexicana, para la prevención del sobrepeso, la obesidad y las enfermedades crónicas no transmisibles para el período 2018-2028. Objetivo: Describir el diseño, el desarrollo y la implementación de NutriNet-Salud México a partir del modelo francés NutriNet-Santé France 2008-2018. Método: La plataforma NutriNet-Salud México es la base digital para el desarrollo de un sistema de información en salud -para un estudio de cohorte prospectivo programado para 10 años

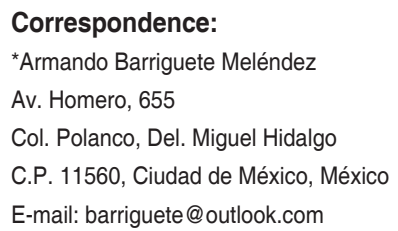

Date of reception: 24-01-2017

Date of acceptance: 13-09-2017

DOI: 10.24875/CIRUE.M18000002
Cir Cir. 2018;86:4-14

Contents available at PubMed www.cirugiaycirujanos.com 
(2018-2028) - con un sitio web dedicado cuyo desarrollo permite tener varias poblaciones de estudio que responden un conjunto inicial de cinco cuestionarios autoaplicables validados en población mexicana. Resultados: La información obtenida permitirá desarrollar investigación aplicada, conocer y vigilar los aportes alimentarios y el estado nutricional de la población, evaluar el impacto de acciones de salud pública sobre el comportamiento alimentario y el estado nutricional, y comparar poblaciones entre países (México, Francia, Bélgica y Suiza) e institutos nacionales, universidades y Estados. Conclusiones: NutriNet-Salud México permitirá coadyuvar en investigación y acción pública, especialmente en la orientación de políticas públicas de México en materia de nutrición. Los elementos científicos aportarán recomendaciones nutricionales adecuadas a diferentes poblaciones, y permitirán acceder a una representativa muestra poblacional nominal a bajo costo y en tiempo real con doble abordaje de e-epidemiología: estudio de cohorte para identificar causalidad y estudios transversales periódicos (investigación descriptiva, monitoreo y evaluación).

PALABRAS CLAVE: NutriNet-Salud México. Sistema de información en salud. Nutrición. Obesidad. Enfermedades crónicas no transmisibles.

\section{Introduction}

Nutrition and obesity-related chronic non-communicable diseases, such as type 2 diabetes mellitus (DM2), hypertension, cardiovascular diseases (CVD) and cancer, represent in many countries a major public health problem due to the high morbidity and mortality rates and expenditure for their medical care. Each year, 38 million people die in the world owing to these diseases. More than 14 million deaths related to chronic diseases occur between 30 and 70 years of age, and out of these, $85 \%$ occur in developing countries. In Mexico, CVD, DM2 and cancer account for more than $50 \%$ of annual deaths 1 .

Obesity is a serious health problem in Mexico². Currently, approximately $70 \%$ of adults older than 20 years, i.e., around of 49 million people, suffer from overweight or obesity ${ }^{3}$, as well as $35 \%$ of school age children (nearly 12 million). The 2012 National Health and Nutrition Survey (ENSANUT - Encuesta Nacional de Salud y Nutrición) $)^{2}$ identifies a prevalence of $9.2 \%$ of adult population in Mexico (around 6.6 million) diagnosed with diabetes mellitus; however, the prevalence reaches nearly $14 \%$ if undiagnosed individuals are included $^{3}$.

Only in 2008, total cost of obesity was calculated at 67 billion pesos, which is the direct annual cost in medical care for the public health system for the 14 complications deriving from four of the diseases associated with obesity: DM2, CVD, breast cancer and osteoarthritis. Should the same trend continue, costs might reach between 151 and 202 billion pesos in $2017^{4}$.

Chronic diseases have a complex etiology, and genetic, biological, behavioral and environmental factors play an important role. Modifiable lifestyle factors, such as physical activity, sleep duration, eating habits and alcohol and tobacco consumption, considerably contribute to the development of the most common and deadly chronic diseases.

Given that these problems usually originate in the first years of life, and are maintained and reinforced with age, it is important to develop interventions in a timely, constant and long-term manner, which not only promote healthy habits, but also allow people to learn to observe, discover and know themselves through their own behaviors. Hence the interest in being able to nominally follow large populations for long periods of time (at least 5 to 10 years), with different profiles and in safe digital platforms that enable complex analyses and preserve confidentiality ${ }^{5}$.

Currently, there are prevention strategies that have demonstrated their effectiveness in improving health through lifestyle changes; complementarily, this has contributed to the awareness on population habits. However, it is essential for individuals to learn to make informed decisions about their behavior and treatment based on daily results, and this is where an automated registration system can be highly efficient.

Scientific evidence points out the importance of developing longitudinal cohort studies, with medium and long-term observation periods, complemented by comparative studies, to dynamically know the behavior and the different conducts of large populations, and thus identify risk factors and elements for health protection $^{6-9}$.

In the particular case of Mexico, the Federal Ministry of Health develops and implements the National Strategy for the Control and Prevention of Overweight, Obesity and Diabetes ${ }^{10}$, which integrates various actions in three main pillars: 1) population habits 


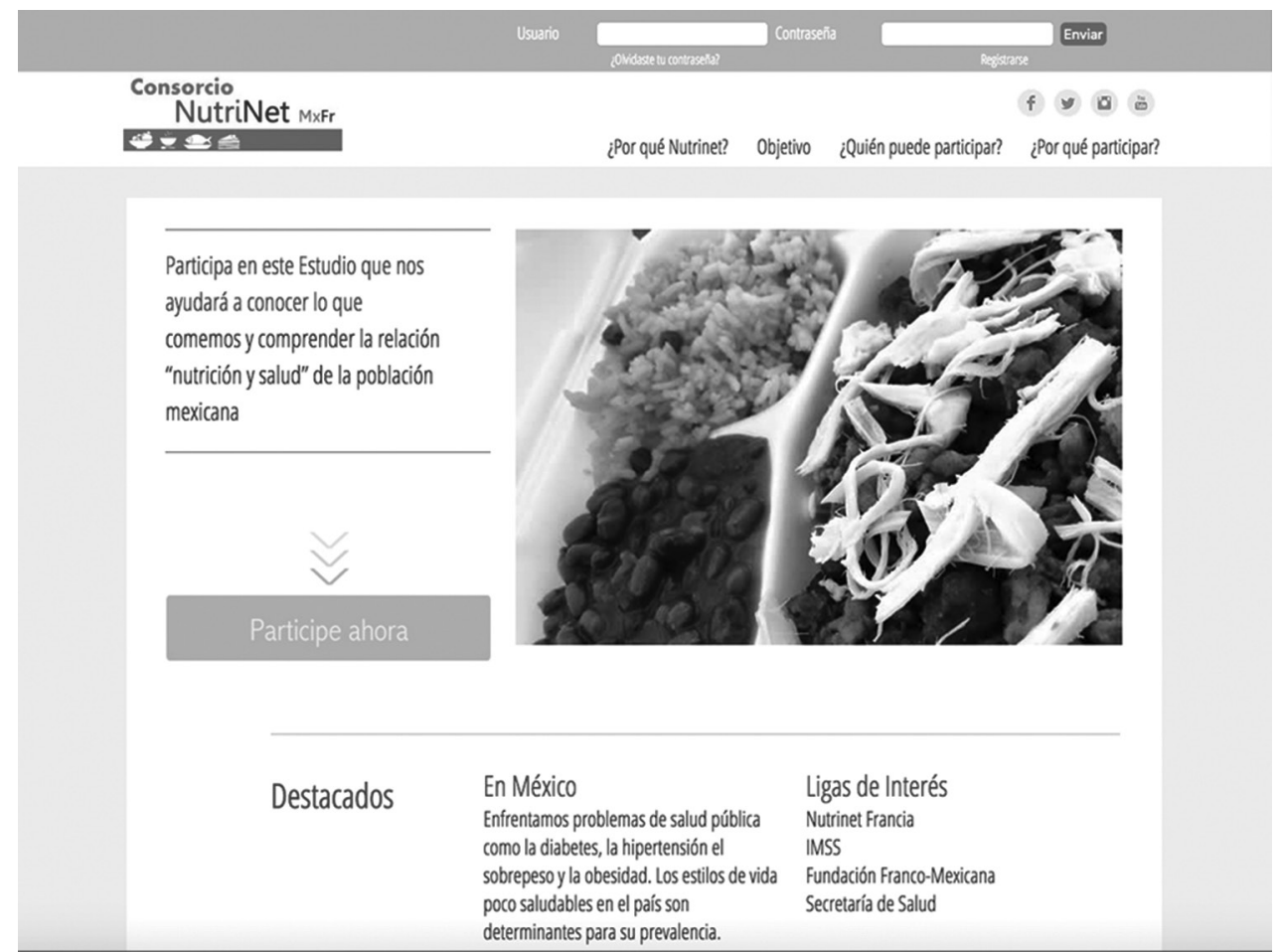

Figure 1. NutriNet-Salud México page.

modification through strategies of social marketing in health and promotion of healthy lifestyles; 2) reinforcement of the quality of medical care, management and prevention of obesity and diabetes at primary care, with greater emphasis on medical personnel training and updating; and 3) modification of the obesogenic environment through health regulation and fiscal policy, thereby reducing the availability and consumption of foods with high caloric density. Within the framework of this strategy, the Mexican Observatory of Non-Communicable Diseases (OMENT - Observatorio Mexicano de Enfermedades No Transmisibles) was inserted, with the purpose to improve epidemiological surveillance of these diseases, which includes the monitoring of obesity, in order to provide information to the public of users and decision makers with regard to the assessment and development of public policies.

For these reasons, the systematic record of daily activities and feedback based on the best possible evidence can be an adequate and effective strategy for positive reinforcement, as well as for control and prevention of chronic non-communicable diseases, in addition to serving as a short-term personal, family and institutional, and mid-term state and national longitudinal guide. By generating data based on the observation of the nutritional habits of different Mexican populations, NutriNet-Salud México will become a strategic ally of the National Plan and OMENT.

\section{Method}

NutriNet-Salud México is a digital 2.0 web-based platform (Fig. 1) for the study of a 10-year prospective cohort. It implies the development of an e-epidemiology instrument for the creation of a health information system in Mexico, based on the French NutriNet-Santé model ${ }^{11}$, through self-administered questionnaires validated for the Mexican population.

NutriNet-Santé uses online self-administered questionnaires to identify and know the different population groups through their nutritional and health behaviors ${ }^{12,13}$, and crosses the compiled information with the collection of biological data, which allows to closely explore the French population habits and their consequences $^{14-16}$. This way, the NutriNet-Santé platform turns out to be a methodological model to be consulted and taken into account to follow-up on habits and behaviors of the population with regard to nutrition and lifestyles, which is very useful in the formulation of actions and policies in emerging countries, not only applicable to Mexico, but also to other Latin American countries based on our experience.

NutriNet-Salud México offers a great opportunity to access to a representative sample of nominal 
population at low cost and in real time, with an e-epidemiology double approach: a cohort study that allows identifying the causality (etiological research), and cross-sectional studies that are repeated (descriptive research, monitoring and assessment). It also offers a great opportunity to include other cohort studies, benefiting from low cost, continuity and association with the lines.

Academic, research and health governance institutions collaborate to the NutriNet-Salud México project. It relies on the participation of seven National Health Institutes: Nutrition, Public Health, Perinatology, Cardiology, Psychiatry, Geriatrics and Cancerology; three Universities: Autonomous University of Guadalajara, University of Guadalajara and Ibero-American University; two state health systems: State of Mexico and Michoacán; two civil society organizations: Fundación Franco Mexicana para la Medicina IAP and Fomento de Nutrición $A C$; the Federal Ministry of Health and the Mexican Institute of Social Security (IMSS - Instituto Mexicano del Seguro Social). All of them participate with defined collaborations for the clarification of that which Mexicans eat and its nutritional composition, identification of nutrition-related health problems and subsequent analysis of available information as research lines of interest to each institution.

\section{NutriNet-Salud México developmental stages}

The construction of the NutriNet-Salud México platform is planned in five stages, following the line of the French study:

\section{DEFINITION OF PRIORITY HEALTH RESEARCH AXES}

With the purpose to stimulate the development of high-level human resources allocated to research and to promote the bond between research and the development of technical skills, the involved organizations worked in the definition of priority health research axes of interest for each institution, in order to strengthen scientific research of excellence, and contribute to improving population health and well-being through the generation and efficient use of new knowledge.

NutriNet-Salud México is structured in such a way that it facilitates the dissemination and use of information. The strategy to spread and disseminate statistical information includes a biannual record cutoff, by means of which the participating institutions work as responsible for the preparation and dissemination of official figures, statistical reports and scientific publications, always with a contribution to public policy.

\section{DeVELopMENT OF QUESTIONNAIRES}

The French NutriNet-Santé model includes five questionnaires: 1) economic, demographic, social and lifestyle aspects; 2) health; 3) anthropometric; 4) physical activity and sedentariness; and 5) food and registration form. The translation-retranslation process (French-Spanish-French) was carried out by a specialized translator, reviewed by specialists, except for the food questionnaire (see below) (Fig. 2).

- Questionnaire on economic, demographic, social and lifestyle aspects: information is collected regarding marital status, number of children and grandchildren, number and characteristics of family members, current job (or last occupation), diplomas, professional category of the spouse and level of education, smoking history (type, amount, duration, passive smoking), alcohol consumption (type, amount, frequency) and income.

- Health questionnaire: information is collected regarding the medical history, past history, current use of medications, dietary supplements, family medical history, first-degree relatives causes of death (where appropriate) and, for women, obstetric history, pregnancy, menopause, contraception and hormone replacement therapy at menopause where appropriate.

- Anthropometric questionnaire: includes questions related to height, weight, hip and waist circumference (it includes instructions to measure it properly), as well as history of weight, practice of restrictive diets (history, type and reason) and body self-perception.

- Physical activity and sedentary lifestyle questionnaire: the self-administered questionnaire web-based version of the International Physical Activity Questionnaire (IPAQ) is used ${ }^{17}$. Physical activity is described according to three levels of exercise intensity (walking or moderate or vigorous activity), exercise frequency per week (days per week) and daily duration of each performed activity.

- Food questionnaire: to reduce the error produced by intra-subject variability in food consumption, the "nutrinaut" will be asked to record 3 days 


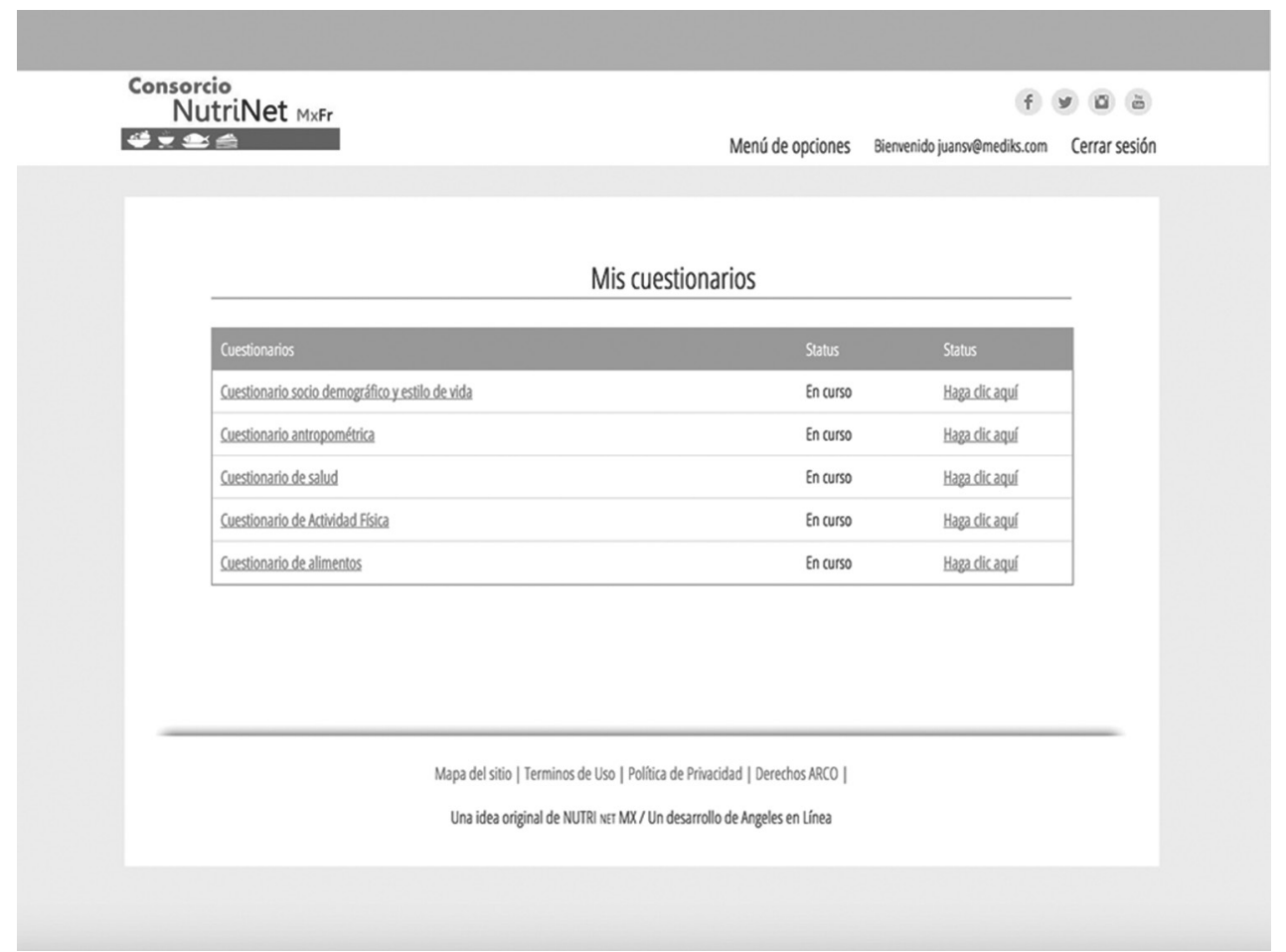

Figure 2. Page where NutriNet-Salud México initial questionnaires are observed.

within a period no longer than 1 week. The 3-day information will be considered for analysis (see below).

- Additional questionnaires: as part of the monitoring program, the "nutrinauts" will complete additional questionnaires each year. In doing so, they will receive an automatic e-mail to inform them on the need to complete a new questionnaire in their personal space on the NutriNet-Salud México website, associated with the research lines proposed by the participating institutions.

- Auxiliary protocols: in the context of auxiliary protocols that address different topics of scientific interest, including specific questionnaires for the general population or for subsamples chosen according to particular phenotypes (age, gender, region, health status, etc.) will be possible. Participants will be invited to fill out this questionnaire once they are connected to the study website. The interface will allow administrators to create research groups and determine if participants have a profile or way of answering questions that fall within certain categories, or if they correspond to certain selection criteria in order to group the participants (e.g., all males older than 45 years who do not smoke).
For the instruments, except for the physical activity and sedentary lifestyle, and food questionnaires, a pilot test was conducted in three groups of people, 42 in total, including students, academics and janitorial staff, taking into account the educational level of each one. This test allowed to perform the relevant adjustments to each instrument and the questionnaires were applied again with the same group, in order to corroborate if the answers agreed with those of the first application, and among the results, only $2 \%$ variation average was identified for each one of the answers.

The food questionnaire of the NutriNet-Salud Mexico platform, as well as NutriNet-Santé in France, will be applied with the 24-hour reminder (R24) ${ }^{18}$. This dietary evaluation instrument allows the assessment of food and beverages consumption during the 24 hours prior to the application of the questionnaire. Applying three R24 for each data collection phase is planned. The first advantage of R24 is that all the food and drinks consumed by any individual can be included, given that it is an open instrument; the second one, it allows estimating the consumed amounts. Its disadvantage is that, by being based on the subject's recall to report that which is consumed, it makes it difficult to establish the consumed amounts and many times consumption is overestimated or underestimated. 


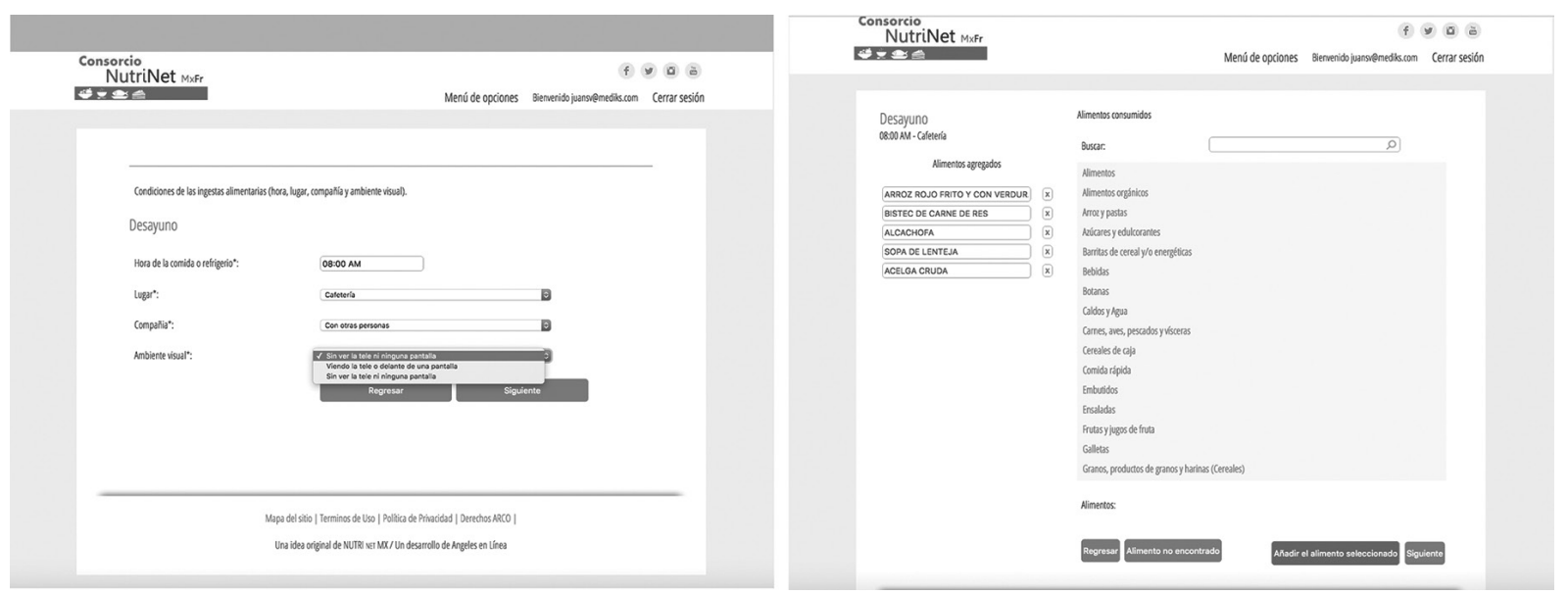

Figure 3. Images that show how the foods consumed in 24 hours are to be described in detail.

Table 1. Nutrinet-Salud México food database integration

\begin{tabular}{|c|c|c|c|}
\hline Database & Contribution & Data & Comments \\
\hline Mexican foods and dishes & INCMNSZ & $\begin{array}{l}\text { Data on nutrimental composition measured in } \\
\text { Mexican foods and dishes }\end{array}$ & $\begin{array}{l}\text { INCMNSZ data to be published. } \\
\text { It is the only Mexican source of foods and } \\
\text { dishes direct nutrimental analysis }\end{array}$ \\
\hline $\begin{array}{l}\text { Foods and dishes reported } \\
\text { in ENSANUT }\end{array}$ & INSP & $\begin{array}{l}\text { List of } 1217 \text { foods and dishes } \\
\text { Nutrimental analysis (USDA or INCMNSZ 2007) }\end{array}$ & $\begin{array}{l}\text { Increases error due to nutrimental composition } \\
\text { calculation and use of USA database }\end{array}$ \\
\hline $\begin{array}{l}\text { Recipes of dishes reported } \\
\text { in ENSANUT }\end{array}$ & INSP & $\begin{array}{l}\text { List of } 322 \text { dishes with selected and standardized } \\
\text { recipe and their nutrimental analysis (USDA or } \\
\text { INCMNSZ 2007) }\end{array}$ & $\begin{array}{l}\text { Increases error due to selection of recipes and } \\
\text { nutrimental composition calculation and use of } \\
\text { USA database }\end{array}$ \\
\hline SMAE foods & SMAE & $\begin{array}{l}\text { List of SMAE foods with nutrimental analysis from } \\
\text { different sources }\end{array}$ & $\begin{array}{l}\text { Increases error due to calculation } \\
\text { Not all nutrients of all foods are analyzed } \\
\text { Varied food composition bases for calculation }\end{array}$ \\
\hline
\end{tabular}

ENSANUT (Encuesta Nacional de Salud y Nutrición): National Health and Nutrition Survey; INCMNSZ (Instituto Nacional de Ciencias Médicas y Nutrición Salvador Zubirán): National Institute of Medical Sciences and Nutrition "Salvador Zubirán"; INSP (Instituto Nacional de Salud Pública): National Institute of Public Health; SMAE (Sistema Mexicano de Alimentos y Equivalentes): Mexican System of Foods and Equivalents; USDA: US Department of Agriculture.

Owing to these limitations, methodologies are used to reduce error. A new version that has been used is multistep R24, which includes five steps that help the individual to "review" the reported consumption several times to help him/her remember ${ }^{18}$. The individual starts from a quick list of consumed foods and drinks, and then describes in detail each of the meals he/she had, describing all the foods or dishes he/she recorded at each meal (Fig. 3). Foods are identified by means of a search engine or can be found in general categories (e.g., dairy, sweetened beverages, side dishes, snacks, etc.). In addition, the user can add extra ingredients for the dishes, such as salsas, cream or cheeses, which are very common in our country. To improve portion estimation, NutriNet-Salud México includes visual tools, such as pictures of different portions of food.

The working methodology of the NutriNet-Salud México food questionnaire is divided in three stages:
- First stage: list of foods, dishes and beverages. A selection of foods and beverages was made on which the questionnaire would build upon, which included nutritional information in order to be able to perform the consumption analysis. The National Institute of Public Health (INSP - Instituto Nacional de Salud Pública) has a list of the most consumed foods and beverages, reported by a representative group of Mexicans as a result of the application of 2012 ENSANUT $^{19}$. The list of the most consumed foods and beverages according to 2012 ENSANUT was originally analyzed per 100-gram food portions, taking as reference the US Department of Agriculture (USDA) nutritional information database ${ }^{20}$ and the Nutritional Value Tables of Mexican Foods ${ }^{21}$. In case of missing information, the Mexican System of Equivalent Foods (SAME - Sistema Mexicano de Alimentos Equivalentes) was also used ${ }^{22}$ (Table 1). 


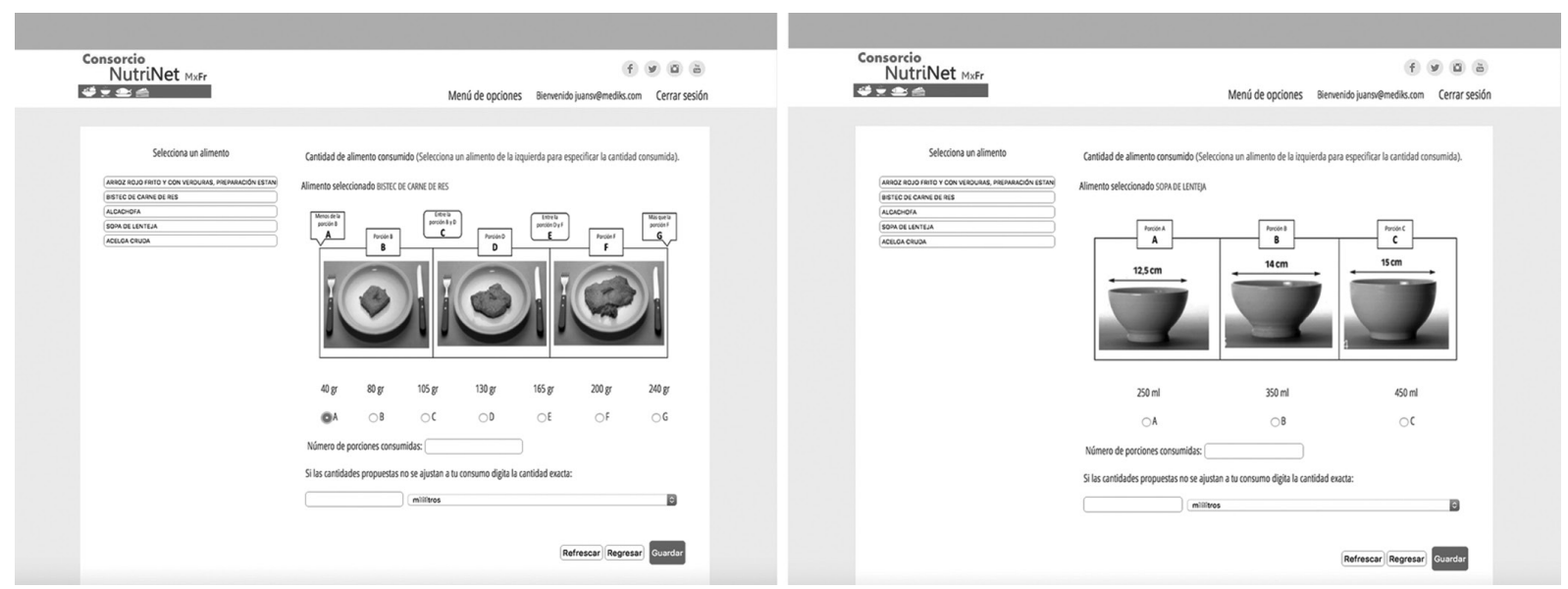

Figure 4. Images showing the visual presentation of consumed food portions.

Table 2. Sources of food/dishes portions pictures

\begin{tabular}{llll}
\hline Pictures & Contribution & Details & Comments \\
\hline Pictures of Texican foods & UDG & $\begin{array}{l}\text { Pictures of } 359 \text { foods and beverages, showing } \\
4 \text { different portion sizes }\end{array}$ & $\begin{array}{l}\text { Originating from a manual for portion } \\
\text { estimation (still to be published) }\end{array}$ \\
$\begin{array}{l}\text { Pictures of Mexican foods } \\
\text { and dishes }\end{array}$ & SMAE & $\begin{array}{l}533 \text { pictures showing different food and } \\
\text { dishes equivalents }\end{array}$ & $\begin{array}{l}\text { Most pictures were taken as } 1,2 \text { or } 1 / 2 \\
\text { equivalents }\end{array}$ \\
$\begin{array}{l}\text { Pictures of French foods } \\
\text { and dishes }\end{array}$ & $\begin{array}{l}\text { Nutri-Net Santé } \\
\text { France }\end{array}$ & $\begin{array}{l}89 \text { original pictures of the French } \\
\text { questionnaire were used } \\
\text { They show minimum portion sizes }\end{array}$ & $\begin{array}{l}\text { Only those foods that are similar or equal in } \\
\text { France were considered }\end{array}$ \\
\hline
\end{tabular}

SMAE (Sistema Mexicano de Alimentos y Equivalentes): Mexican System of Foods and Equivalents; UDG (Universidad de Guadalajara), University of Guadalajara.

The food questionnaire also aims to include a list of industrialized foods, where, unlike the list of foods and beverages, the information will be obtained from the nutrition facts label included in their commercial presentation.

- Second stage: pictures. The access to photographs for the food questionnaire generates a unique approach, since exclusively verbal or written description is exposed to interpretation and error. Visual estimation offers different portion sizes of frequently consumed foods, and is linked to weight in grams and nutritional information (Fig. 4). The selection of photographs was made according to previous works in Mexico, with the work of the University of Guadalajara, Mexican food photo album, standing out, which includes pictures of 359 foods $^{23,24}$. The methodology used for the preparation of the photographs was previously validated ${ }^{25}$ and is similar to that of NutriNet-Santé26. The pictures included in the food questionnaire were supplemented with those of SMAE foods, which had never been used or published, as well as with some of the original NutriNet-Sante site that could be used in Mexico (Table 2). With the available information, a detailed review of the list of foods and beverages that have a photograph was carried out, and as a result, NutriNet-Salud México includes, for the first time in Mexico and Latin America, a database of foods and beverages with a picture associated with the nutritional information resulting from the coding in grams of each reported portion or standard portion photograph. Foods or drinks that were deemed as not requiring a representative picture were included in the platform assigning the weight in grams of standard portions that the user can report (pieces, cups, etc.). From the list of foods and beverages, it was determined that some missing items did require a picture $(n=34)$. Following the same methodology as in France (three sessions: one pilot run and two photo sessions), the taking of pictures was carried out.

- Third stage: flow of information and structure of the questionnaire and web page. The NutriNet-Santé food questionnaire was reviewed in order to observe the same structure in the Mexican platform. The food categories (e.g., meats, etc.) that are displayed when the user registers a 
meal (e.g., breakfast, lunch, dinner, snack), as well as a subcategory (e.g., beef, pork, poultry, fish and seafood, etc.) were reviewed within each general category. Although the platform should be almost identical to the NutriNet-Santé platform, taking into account the culture and eating habits in Mexico, some adaptations were made. A pilot study will be carried out for the use of this questionnaire within the platform, which will allow adjustments and changes to be made as required. Finally, it will be validated by comparing its performance with the application of the R24 in person, in a sufficient sample of individuals.

\section{Preparation of ethical and legal instruments}

NutriNet-Salud México, in order to achieve its main objective, requires that the user, called "nutrinaut", enters in the platform a series of data that, according to our laws, in Mexico are considered personal data and are classified as sensitive. For this, the information collected through the NutriNet-Salud México platform complies with specifications defined in the Mexican laws, and prior to filling out the information and sending it, the nutrinaut will know and must accept the Informed Consent and the Notice of Privacy, in addition to being free to withdraw from the study at any time. It should be noted that the performance of this study was approved by the Research Committee and the Research Ethics Committee of the National Institute of Medical Sciences and Nutrition.

\section{Programming and generation of the databases}

The NutriNet-Salud México platform, in order to be able to fulfill its function, requires the capture and storage of data taken from a series of questionnaires filled out by the subject under observation. The purpose is to retrieve this information and being able to carry out processes therewith. To achieve this functionality, a relational database system was designed based on the following concepts: 1) standardization of the information captured by the different questionnaires; 2) capture of the questionnaires in such a way that the recovery of their information is facilitated, which led the group to design a relational database system that allows the capture of the six original questionnaires (the basic kit plus the registration questionnaire), and later a third restriction was announced that had not been considered; and 3) permanent addition of new questionnaires.

Permanent addition of new questionnaires was a not previously considered restriction that led the group to question the original design, since the inclusion of new questionnaires meant not insignificant modifications to the database design. Generating a model of the database was then proposed, building upon a more abstract level, with the handling of the dictionary as if it was another data structure entering the system, in such a way that it would allow the inclusion of new questionnaires without substantial modifications to the system. This led to the generation of an innovative model, where each dictionary was modeled as a sequence of triplets: <question, type, possible_answers>; although this abstraction added complexity to the design of the database, allowed a more adequate management of the structure of each dictionary.

In the current system, new questionnaires represent one more entry for the system, which automatically manages its capture and retrieval of information, and in addition it provides the possibility to analyze the captured information with big data techniques, and it is enriched with visualization tools that allow to observe how the information is grouped and dispersed.

Considering the type of project, its use, transaction and storage needs, and possibilities of integration with other platforms, NutriNet-Salud México uses MySQL ${ }^{25}$ (free database management system) and the MySQL-admin package (graphical environment for administration, auxiliary in the management of software, databases, users, resources and safety).

\section{Creation of the web page and interface}

Regarding the development and promotion of the project and registry of participants (http://www.mexico-francia.mx/NutriNet/and http://www.NutrinetSalud-Mexico.mx), a structure similar to that of the French pioneer version was proposed and implemented, whereby a better user-server interaction is allowed, considering current global navigation trends.

According to the results of the survey on advantageous use of information and communication technologies in Mexico's households, conducted by the National Institute of Statistics and Geography in 2012, $32.2 \%$ of households in the country had a computer, a percentage that increased by $8.9 \%$ in one year. In addition, $26 \%$ of households had an Internet connection, showing a growth of $13.4 \%$ in relation to 2011 . In 
2014, a total of 53.9 million users were reported, which accounted for $51 \%$ of the population, with an annual growth of $5.3 \%$. In Mexico City, $60 \%$ of its total population has Internet access, and $70 \%$ of Internet users are 18 years of age or older. In addition, the totality of government and higher education entities have access to the Internet ${ }^{26}$. This, for a health information system based on the use of Internet, such as NutriNet-Salud México, offers a great opportunity to access to a representative population sample at a low cost and in real time.

Once the development stage is completed, the platform launch will be initiated:

- Institutional execution stage, lasting 6 months, in the institutions and the two health systems of the States that participate in Nutri-Net-Salud México, health and education personnel, students, patients and their families, with a cutoff for data analysis, one scientific publication and public health recommendations.

- After 6 months, nation-wide launch of large campaigns through different media for the recruitment of volunteers.

- Stage for the development of a virtual supermarket and conduction of a randomized trial on the impact of nutritional information systems.

\section{Results}

NutriNet-Salud México is a prospective cohort study, scheduled for a 10-year period (2018-2028) using a dedicated website where, once the "nutrinaut" completes the questionnaires, the information obtained on the platform will allow:

- Development of research applied to the field: study of the relationships between contributions in terms of energy, nutrients, food and eating behaviors, and physical activity, with sociological, ecological, cultural, biological, etc. determinants of eating behaviors, nutritional status and health status; monitoring of population food consumption, physical activity and nutritional and health problems evolution and times; quality of life; eating disorders, depression, cognitive impairment, etc.; incidence of overweight and obesity, hypertension, metabolic syndrome, cancer, DM2 and cerebrovascular disease (CVD); overall and specific mortality (for cancer, DM2, CVD and related conditions); and understanding of determinants and eating and nutritional behaviors.
- Diagnosis (nutrition and physical activity) as the basis for the development of interventions and strategies, to promote a healthy lifestyle in the population.

- Assessment of the impact of public health actions on eating behavior and nutritional status, campaigns, programs, etc. (in terms of knowledge, perception and efficacy).

- Comparison of Mexican population, National Institutes, Universities and States, with France, Belgium and Switzerland.

It is important to point out that one of the great strengths of Nutrinet-Salud México is that it has enabled the integration of multiple health-related organizations and institutions in Mexico, and that sharing information -as in this case, information related to food databases, including nutritional value, composition and images, whereof there was no precedent in our country-, has been a great step for this research project, observing the French model, which is the basis for the creation of the system, but emphasizing its adaptation to that which Mexicans eat.

Databases were unified, in the first place the INSP database, which emerged from 2012 ENSANUT and includes consumed foods reported by a representative group of Mexicans during this National Survey. On the other hand, the National Institute of Medical Sciences and Nutrition "Salvador Zubirán" (INCMNSZ) completed in 2016 the updating of the Tables of Mexican food nutritional composition, which have been shared to be used as part of the Nutrinet-Salud México food questionnaire. In this second database, some nutrients were measured directly in the foods, and in those that were missing, the information was completed with the USDA database. As for the dishes related to the publication What and how do Mexicans eat? Food consumption by the urban population ${ }^{27}$, a study that was possible thanks to the support of FUNSALUD's Nestlé Fund, INSP generated a database of recipes for each of them, in order to facilitate their nutrimental analysis. Nutrinet-Salud Mexico includes some of these recipes and complements the list of dishes. An analysis of common Mexican recipes is performed with the Food Processor SQL software, which allows to include Mexican ingredients or to select from a broad list of foods and beverages; to complement the information, the Mexican Food System was reviewed. Regarding industrialized foods, although the aforementioned databases include several, in the Nutrinet-Salud México food questionnaire, the list was completed using the nutrimental information on 
the product label, including different commercial brands.

Thus, the Nutrinet-Salud Mexico food questionnaire, as the first result of this platform, will include the most complete food, dishes and beverages database, which will be able to analyze the nutritional content according to currently available main sources.

\section{Discussion}

The purpose of this project is to have information available on nutrition and health habits of the population through an e-epidemiology model, a "health information system", which will provide relevant data for the design of public health policies in Mexico by: 1) providing scientific evidence to define the public nutritional health recommendations adapted to the different populations; 2) identifying barriers to take measures and guide the definition and terms of public health actions; and 3) experimentally test the impact of public health interventions prior to their application or as part of the measures introduced in the population (impact in terms of knowledge, perception, efficiency, and changes in behavior and practices).

NutriNet-Health Mexico implementation will allow, in the short term, to obtain information on nutrition-related risks and protective factors, identify the determinants of nutritional status and their interactions, and compare the results with similar systems in France, Belgium and Switzerland. Furthermore, based on the Mexican experience, the platform will also be able to be shared with Latin American countries, with Colombia, El Salvador and Nicaragua among those interested, just to mention a few.

NutriNet-Salud México is the result of several months of teamwork of those who make up the network (RED) of participating institutions, adding value to the platform through research protocols on nutritional outcomes, adding the experience of different working groups to generate a complete and general database of Mexican foods with nutrimental information, complemented with pictures of portions.

\section{Acknowledgements}

To the co-authors and members of RED NutriNet-Salud México: M. Abdo (AMC), S. Barquera (INSP, Mexico), A. Basdevant (CHU Pitié Salpêtrière, Paris, France), T. Baubet (Université Sorbonne Paris 13 Cité, Paris, France), JA Barriguete Meléndez (INCMyNSZ, CEFM, AMC), J. Baulieux (Académie Nationale de
Médecine, Paris, France), A.C. Benhammou (Ministère de la Recherche et de l'Enseignement Supérieur, Paris, France), M.F. Bernal-Orozco (Universidad de Guadalajara, Mexico), R.H. Bourges (INCMNSZ, Mexico), J. Dávila Torres (IMSS, Mexico), C. Aranza (Secretaría de Salud, Estado de Michoacán de Ocampo, Mexico), M.F. Cachera (Université Sorbonne Paris Cité, Paris, France), Z.I.L. Canela (Instituto Nacional de Cardiología, Mexico), J.A. Cardona (Instituto Nacional de Perinatología, Mexico), F. Cruz-Vega (IMSS; Academia Mexicana de Cirugía, Mexico), F. Chico (Consejo Estratégico Franco-Mexicano, Mexico), R.E. Colin (Instituto Nacional de Cardiología, Mexico), T.J. Dávila (Academia Mexicana de Cirugía, Mexico), S. Elizondo-Argueta (IMSS, Mexico), P. Galán (Université Sorbonne Paris 13 Cité, Paris, France), M.C. Gómez (Secretarís de Salud, Estado de México, Mexico), H.J.A. González (Instituto Nacional de Cardiología, Mexico), L.M. Gutiérrez (Instituto Nacional de Geriatría, Mexico), R.J.F. González (Secretaría de Salud Gobierno Federal, Mexico), S Hercberg (Université Sorbonne Paris 13 Cité, Paris, France), M. Hernández-Avila (INSP, Mexico), L.G. Hernández (Fundación Franco-Mexicana para la Medicina IAP; Secretaría de Salud del Estado de Colima, Mexico), B. Jácome (Universidad Autónoma de Guadalajara, México), N.E. Jaramillo (Secretaría de Salud Gobierno Federal, Mexico), D. Kershenobich (INCMNSZ, Mexico), P. Kuri-Morales (Secretaría de Salud Gobierno Federal, Mexico), E.A. Lara (Secretaría de Salud del Estado de Colima, Mexico), E.G. Leal (Instituto Nacional de Cardiología, Mexico), T. Le Luong (Institut National de Prévention et d'Éducation pour la Santé, France), F.L. López (Instituto Nacional de Cardiología, Mexico), K.M. López (Secretaría del Estado de México, Mexico), M.A. Martínez Ríos (Instituto Nacional de Cardiología, Mexico), R.M. Madero (Instituto Nacional de Cardiología, Mexico), A. Meneses (Instituto Nacional de Cancerología, Mexico), L. Magaña (INSP, Mexico), M.A. Medina Mora (Instituto Nacional de Psiquiatría, Mexico), M.A. Mejía (INSP, Mexico), L.J. Morales (INCMNSZ, Mexico), M.R. Moro (Maison de Solenn, University of Paris Descartes, Sorbonne Paris Cité, France), J.M. Oppert (CHU Pitié Salpêtrière, Paris, France), B. Palacios-González (Universidad Iberoamericana, Mexico), O. Perichart (Instituto Nacional de Perinatología, México), A.B. Pérez-Lizaur (Universidad Iberoamericana, Mexico), S.R. Posadas (Instituto Nacional de Cardiología, Mexico), R.C. Posadas (Instituto Nacional de Cardiología, Mexico), R. Ridaura (INSP, Mexico), G.F.J. Roldán (Instituto Nacional de 
Cardiología, Mexico), J. Tapia (AMC), A.M. Vallejo (Instituto Nacional de Cardiología, Mexico), B. Vizmanos (Universidad de Guadalajara, Mexico), and C.A. Aguilar Salinas (INCMNSZ, Mexico).

\section{Ethical responsibilities}

This project has the approval of the INCMyN scientific and ethics committee, Reference 1965, valid through July 25, 2018.

Protection of people and animals. The authors declare that no experiments have been conducted on humans or animals for this research.

Confidentiality of data. The authors declare to have followed the protocols of their work centers on the publication of patient data.

Right to privacy and informed consent. The authors declare that no patient data appear in this article.

\section{Funding}

The present study did not receive any financing for its performance. Each of the authors contributed with their work without receiving any subsidy.

\section{Conflict of interests}

There are no conflicts of interests involving any of the authors.

\section{References}

1. World Health Organization. Noncommunicable diseases country profiles 2014. New York: WHO; 2014

2. Olaíz G, Rivera Dommarco JA, Shamah T, Roja R, Villalpando S, Hernández Ávila M. Encuesta Nacional de Salud 2012. Cuernavaca, México: Instituto Nacional de Salud Pública; 2012.

3. García-García E, De la Llata Romero M, Kaufer-Horwitz M, Tusié-Luna MT, Calzada-León R, Vazquéz-Velázquez V, et al. La obesidad y el síndrome metabólico. Un reto para los Institutos Nacionales de Salud. Rev Invest Clin. 2009;61:333-46.

4. Álvarez del Río F, Gutiérrez-Delgado C, Guajardo-Barrón V. Costo de la obesidad: las fallas del mercado y las políticas públicas de prevención y control de la obesidad. En: Rivera Dommarco JA, Hernández Ávila M, Aguilar Salinas CA, Vadillo Ortega F, Murayama Rendón C, editores. Obesidad en México: recomendaciones para una política de Estado. México: UNAM; 2012. p. 279-88.

5. Ford ES, Bergmann MM, Kroger J, Schienkiewitz A, Weikert C, Boeing $\mathrm{H}$. Healthy living is the best revenge: findings from the European Prospective Investigation into Cancer and Nutrition-Potsdam Study. Arch Intern Med. 2009;169:1355-62.

6. Deglaire A, Méjean C, Castetbon K, Kesse-Guyot E, Hercberg S, Schlich P. Associations between weight status and liking scores for sweet, salt and fat according to the gender in adults (The NutriNet-Santé study). Eur J Clin Nutr. 2015;69:40-6.

7. Camilleri GM, Méjean C, Bellisle F, Andreeva VA, Sautron V, Hercberg $\mathrm{S}$, et al. Cross-cultural validity of the Intuitive Eating Scale-2. Psychometric evaluation in a sample of the general French population. Appetite. 2015;84:34-42.

8. Szabo de Edelenyi F, Julia C, Courtois F, Méjean C, Péneau S, Galan $P$, et al. Starchy food consumption in French adults: a cross-sectional analysis of the profile of consumers and contribution to nutritional intake in a web-based prospective cohort. Ann Nutr Metab. 2014:64:28-37.

9. Méjean C, Szabo de Edelenyi F, Touvier M, Kesse-Guyot E, Julia C, Andreeva VA, et al. Motives for participating in a web-based nutrition cohort according to sociodemographic, lifestyle, and health characteristics: the NutriNet-Santé cohort study. J Med Internet Res. 2014;16:e189.

10. Estrategia Nacional para la Prevención y el Control del Sobrepeso, la Obesidad y la Diabetes. México: Secretaría de Salud; 2013.

11. Hercberg S, Castetbon K, Czernichow S, Malon A, Mejean C, Kesse E, et al. The NutriNet-Santé Study: a web-based prospective study on the relationship between nutrition and health and determinants of dietary patterns and nutritional status. BMC Public Health. 2010;10:242.

12. Touvier M, Kesse-Guyot E, Méjean C, Pollet C, Malon A, Castetbon K, et al. Comparison between an interactive web-based self-administered $24 \mathrm{~h}$ dietary record and an interview by a dietitian for large-scale epidemiological studies. Br J Nutr. 2011;105:1055-64.

13. Hercberg S, Castetbon K, Czernichow S, Malon A, Mejean C, Kesse E, et al. The NutriNet-Santé Study: a web-based prospective study on the relationship between nutrition and health and determinants of dietary patterns and nutritional status. BMC Public Health, 2010;10:242-6.

14. Deglaire A, Méjean C, Castetbon K, Kesse-Guyot E, Hercberg S, Schlich P. Associations between weight status and liking scores for sweet, salt and fat according to the gender in adults (The NutriNet-Santé study). Eur J Clin Nutr. 2015;69:40-6.

15. Lassale C, Péneau S, Touvier M, Julia C, Galan P, Hercberg S, et al. Validity of web-based self-reported weight and height: results of the Nutrinet-Santé study. J Med Internet Res. 2013;15:e152.

16. Medina C, Barquera, S, Janssen I. Validity and reliability of the International Physical Activity Questionnaire among adults in Mexico. Rev Panam Salud Publica. 2013;34:21-8.

17. Conway JM, Ingwersen LA, Moshfegh AJ. Accuracy of dietary recall using the USDA five-step multiple-pass method in men: an observational validation study. J Am Diet Assoc. 2004;104(4):595-603.

18. Gutiérrez JP, Rivera-Dommarco J, Shamah-Levy T, Villalpando-Hernández S, Franco A, Cuevas-Nasu L, et al. Encuesta Nacional de Salud y Nutrición 2012. Resultados Nacionales. Cuernavaca, México: Instituto Nacional de Salud Pública; 2012

19. U.S. Department of Agriculture, Agricultural Research Service, USDA Nutrient Data Laboratory. USDA National Nutrient Database for Standard Reference, Release 24. USDA; 2011.

20. Ledesma JA, Chávez VA, Pérez-Gil RF, Mendoza ME, Calvo CC. Composición de alimentos. 2. ${ }^{a}$ ed. México: McGraw Hill; 2010.

21. Pérez-Lizaur AB, Palacios-González B, Castro AL, Flores Galicia I. Sistema mexicano de alimentos equivalentes. 4. ${ }^{\text {a }}$ ed. México: Fomento de Nutrición y Salud; 2014.

22. Vizmanos-Lamotte B, López-Uriarte P, Hunot-Alexander C, Bernal-Orozco MF, Rodríguez-Rocha NP, Macedo-Ojeda G, et al. Álbum fotográfico de alimentos mexicanos. Guadalajara, Jal. Ediciones de la Noche; 2015.

23. Bernal-Orozco MF, Vizmanos-Lamotte B, Rodríguez-Rocha NP, Macedo-Ojeda G, Orozco-Valerio M, Rovillé-Sausse F, et al. Validation of a Mexican food photograph album as a tool to visually estimate food amounts in adolescents. Br J Nutr. 2013;109:944-52.

24. Hercbeg S, Deheeger M, Preziosi P. Portions alimentaires: manuel photos pour l'estimation des quantités. 3ème ed. Paris: SU.VI.MAZ-Candia/ Polytechnica; 2002.

25. MySQL Editions. Disponible en: https://www.mysql.fr/products

26. Instituto Nacional de Geografía y Estadística. México; 2012. Disponible en: http://www.inegi.gob.mx/est/contenidos/espanol/temas/Sociodem/ notatinf212.asp

27. Arvizu Martínez O, Polo Oteyza E, Shamah Levy T. Qué y cómo comemos los mexicanos. Consumo de alimentos en la población urbana. Instituto Nacional de Salud Pública. Fundación Mexicana para la Salud/ Fondo Nestlé para la Alimentación. México: Grafia Editores; 2015. 